\title{
Association of BMI with Follicular stimulating Hormone and with sperm parameters in males.
}

\author{
Fahmida khatoon ${ }^{1}$, Prof. Ibrahim Hassan Alzahrani ${ }^{2}$., Prof. Hafeezullah Wazir \\ $\mathrm{Ali}^{3}$, Abdelnaser Badawy ${ }^{4}$ \\ Medical Biochemistry dept.1(Northern Boarder University, KSA), Professor and Chairman of \\ Pathology, College of Medicine, King Abdulaziz University, Jedah KSA ${ }^{2}$.Professor of Phsiology, \\ College of Medicine, Northern Border University, Arar, KSA ${ }^{3}$ Faculty of medicine, Mansoura university, \\ Egypt. $^{4}$
}

\begin{abstract}
Objective: To ascertain association of raised BMI with Follicular Stimulating Hormone levels and with sperm parameters among infertile males.

Methods: A cross sectional study was conducted from june 2010 to May 2011. Sample size was 300 males (147 infertile and 153 healthy fertile control subjects) aged 30 and 60 years, selected from the Jinnah Postgraduate Medical Center (JPMC), Aziz Medical Center and Abbasi Shaheed Hospital, Karachi. All the subjects were grouped to BMI criteria (Ascian pacific region for WHO). They were selected by purposive sampling after a detailed medical history and physical examination. Semen analysis was done and blood samples were collected for serum FSH levels. Data was analyzed via SPSS 17.0 by using Analysis of Variances (ANOVA) and independent $t$ test to compare the means and to evaluate the significant association with in the group.

Results: Strong positive correlation between FSH and BMI $(r=0.596, p<0.05)$.Raised BMI appear to have an association with male infertility due to reduction in sperm count in males.

Conclusion: Adiposity is confirmed as risk factor for male infertility in local population.

Key words: BMI, Male Infertility, FSH, Azoospermia, Oligospermia.
\end{abstract}

\section{Introduction:}

Approximately $10-15 \%$ of couples are affected by infertility due to various physio-pathologic problems which come into consideration when the couple fails to conceive after unprotected coitus for more than one year. A male factor can be diagnosed in approximately 50\% of them. The main causes of this disorder for men are associated with various factors, among them are genetic, physiopathologic and anatomopathologic abnormalities, intense and prolonged physical exercises, aging, drugs, and even excessive time of sexual abstinence (1). The epidemiological definition of infecundity recommended by the World Health Organization (2) is incapability to conceive within two years of exposure to pregnancy. It is important to note that the period of exposure used is often one-year in clinical studies whereas five years in demographic studies. Demographic languages describe "fertility" in terms of quantity of offspring rather than the physiological ability to reproduce and therefore, "infecundity" is sometimes used in preference to "infertility". From the formation of male gamete to fertilization, many physiological processes namely spermatogenesis (including spermiogenesis), ejaculation into the vagina, transport of sperm through the female genital tract, capacitation, egg penetration, and decondensation of the head are involved. All of these processes are necessary for the fertilization and early embryonic development. These complicated processes require balanced autocrine, paracrine, and juxtacrine signaling events between different male reproductive functions and optimum hormonal milieu. Failure of these signaling chain of events leads to male infertility (3). Unfortunately, after decades of extensive research, we are still unable to fully understand the regulation of the complex mechanisms underlying the etiology of male infertility at the molecular level, hence, unable to properly diagnose the cause of infertility for many patients. This is exactly the reason why nearly one quarter of all patients with male infertility is labeled as idiopathic. It is, now, presently believed that most of the diagnosis which are marked as idiopathic may have a genetic etiology (3). About $20 \%$ cases of male infertility, which cannot be associated with any other cause, the idea of genetic alterations as being a cause behind it, is being thoroughly scrutinized $(4,5)$.

The most primitive bear witness of understanding the problem of infertility goes back to Egyptians, nearly thousand of years ago. Endocrine function of testicles was first documented by Berthold (18031861).Bernard and Zondek and Ashheim are well known for the discovery of FSH and LH. The advancement in technology coincides with the discovery of new product which results in rapid progress in field of reproductive biology. Infertility is defined as inability of couple to achieve pregnancy after one year of unprotected intercourse.(6). Male factors alone constitute $40 \%-50 \%$ of all infertile study group of infertility (7) and they 
contribute to another $30 \%$ in combination with female factors. Known etiologies of male infertility include cryptorchidism, testicular torsion or trauma, varicocele, seminal tract infections, antisperm antibodies, Hypogonadotropic hypogonadism, gonadal dysgenesis, environmental factors, and obstruction of the reproductive channels and can not neglect genetic factors as well.(8,9) .Most causes of male infertility results in defective spermatogenesis (9).Obesity is proposed for addition to this list obesity is a well recognized risk factor for female infertility (10).

The dilemma of infertility has its societal impacts on effected couples in terms of mental stress and depression (11). The prevalence of infertility in Pakistan is $21.9 \%$ (12). In conservative South Asian culture, a child brings prestige and security to a woman(13) and the desire of having a child is much more intense in Asian part of the world (14).

Similar to women a sex hormone imbalance may affect reproduction in men, and excess weight can affect male hormone levels (15). Obese males usually express a characteristic hormonal profile described as "hyperestrogenic hypogonadotropic hypogonadism"(15).In fact, both total and free blood T levels are shown to be decreased in obese men. Total body fat has been associated with low levels of total and free T It appears that central obesity, in particular, is associated with a decrease in circulating androgen levels. The decrease in androgen levels is proportional to the degree of obesity(17).In obese males, adrenal androgens are diminished as well. A significantly reduced $\mathrm{T}$ to estradiol ratio has been observed among overweight or obese men. Body mass index (BMI) has been demonstrated to affect female fertility; however, little information is available on the impact of BMI on male fertility or semen parameters. Body mass index is associated with alterations in sperm parameters in several reports (18).Previously investigating factors associated with semen quality among couples who visited an assisted reproduction clinic, the prevalence of obesity among men with infertility was 3 times greater than among male partners of couples with idiopathic or female factors(19).Kort et al described the relationship between sperm parameters and BMI in over weight subjects (20). Hinz et al. by his study concluded that obese men presenting having BMI greater than $25 \mathrm{~kg} / \mathrm{m} 2$ shows defective quality of sperm. (21).

Tsai et al (2004) has concluded that low sex hormone binding globulin and T levels, together with low gonadotropins, are frequently observed in diabetic men with severe obesity (22).Outcomes of assisted fertilization greatly influence by excessive body fat in female (23).Conclusion of various studies has also been shown that also female reproductive health is influence by BMI (24).

\section{Prevalence and Geographical Distribution of primary and secondary infertility}

The prevalence and causation of infertility vary from area to area and it can be due to male and female factor or both (25).

Problem of infertility is the same in Pakistan as in the rest of the world but the desire of having a child is much more intense in this part of the world (26).

According to WHO-DHS comparative reports (2004) one in four married women of reproductive age in most developing countries are infertile because of primary or secondary causes (27).

Male infertility can occur due to variety of causes and qualitative abnormalities in semen analysis. The causes are divided into four categories Infertility affects about $8 \%$ to $15 \%$ of the world's population and in about half of the infertile study group men are either the single cause of, or contribute to, the couple's infertility (28).

$>$ The female factor

$>$ The male factor

$>$ Combined factor

$>$ Unexplained Infertility

In $20-25 \%$ of infertile study group the problem is due to the male partner and in $30-40 \%$ the problem is predominantly female, in approximately $30 \%$ of infertile study group abnormalities were found in both partners, and in $15 \%$ no specific factor could be identified (29). Common causes of infertility vary from area to area which include anatomopathologic and physiopathologic anomalies like hormonal abnormalities,genital infections and varicocele(30).

Hypogonadotropic hypogonadism which is a failure of the pituitary gland to produce adequate amount of FSH and LH, can lead to decreased sperm counts and a state of infertility (32). Normal serum concentration of PRL have been shown to exert permissive roles in the male reproductive tract but excessive serum PRL concentration is correlated with infertility, hypogonadism, impotence and galactorrhea (30). The changes in LH and FSH may be the reason that causes the dysfunction of spermatogenesis and sperm maturation in patients with idiopathic azoospermia and oligospermia (32).

The high levels of PRL affect the normal functioning of the testes and indirectly responsible for defective spermatogenesis. (33) Hyperprolactenemia in men is responsible for lack of libido. The rise in the level of PRL may be due to several factors including the use of drugs such as anti-depressants, tranquilizers and anti-vomiting agents. Another cause of high PRL is the presence of small tumors in the pituitary gland which can be detected by CT scan or MRI. Normally treatment with bromocriptine restores normal levels of PRL. In 
case the tumor in the pituitary gland is large, surgical removal of the growth is carried out. PRL is determined in subject with galactorrhea and androgen deficiency and loss of libido (34) High levels of PRL interfere with the production of FSH and LH which in turn will affect the testicular function. In men high PRL concentration causes decrease in sexual impotence. The treatment is usually carried out by the administration of bromocriptine .When the tumor in the pituitary gland is large and not responding to medical treatment, surgical removal of the tumor is the only treatment hyperprolactenemia can cause both reproductive and sexual dysfunction(35). Testes produce $\mathrm{T}$ which plays a significant role in the process of spermatogenesis. If the quantity of this hormone is low then the process of spermatogenesis is bound to be defective. Decrease intra testicular concentrations of $\mathrm{T}$ or other local factors are important for spermatogenesis(36)

Approximately $6 \mathrm{mg} / \mathrm{d}$ of $\mathrm{T}$ is produced by the Leydig cells in a normal young person. $\mathrm{T}$ is bound to SHBG and human serum albumin (HAS). The secretion of $\mathrm{T}$ is pulsatile hence the serum concentrations may fluctuate between 0.3 to $1.2 \mu \mathrm{g} / \mathrm{dl}$. T is converted into dihydroT (DHT) by $5 \alpha$-reductase, which is nearly three times as potent but has a tight binding to plasma proteins. T can either be aromatized to estradiol which occurs in the brain, breast, liver and other tissues. As there is large mass of adipose tissue, aromatization became an important step that causes extra glandular synthesis of estrogen in the body. Approximately $20 \%$ of estradiol is produced by the aromatase activity of leydig cell itself $(37,38)$. For proper functioning of reproductive organs an appropriate milieu of male reproductive hormones must exist for the normal sperm production and survival (39). FSH and LH hormones are secreted from the pituitary gland which receives signals from the hypothalamus and which in turn receives signals from the testes in the form of male hormone and if this signal is lacking the pituitary gland will be geared up in producing more FSH and LH to stimulate the cells in the testes. If these two hormones reach a level which is much higher than the normal level, testes will have stop functioning which is described as testicular failure (40).

Sperm production depends on the concerted action of FSH and LH on the testis. The action of LH is mediated through production of T by the Leydig cells. Since male germ cells possess neither FSH nor androgen receptor, the action of FSH and T occurs through sertoli cells. Although precise function of two hormone remain elusive the existing evidence suggest that both hormone stimulate spermatogenesis.If the levels of FSH and LH are low, the pituitary gland is not producing enough hormone due to some more complex problems. This situation is amenable to treatment by stimulating the hypothalamus or by injecting the same hormones. Isolated FSH deficiency is extremely uncommon, where as abnormal FSH level is rarely seen with normal spermatogenesis (41)

Various genetic syndrome having obesity and hormonal disturbance along with infertility.Prader-Willi syndrome is an inherited disorder which is associated with adult onset diabetes mellitus, hypogonadism, hypomentia, hypotonia at birth and obesity.Low FSH and low LH levels are present in blood and in urine. Defect on chromosome 16 is noticed in $15 \%$ of patient(42).Being overweight is also associated with reproductive dysfunctions. A cluster of metabolic abnormalities, including a tendency to accumulate abdominal fat, as well as resistance to and hyper-secretion of insulin and increased risk of developing type-2 diabetes in later life (43). Therefore, the levels of sex hormone binding globulin might be important only as a marker of altered hormone profiles in obese infertile men(44).

\section{BMI and Sexual dysfunction:}

Erectile dysfunction has been reported to be more common among men with high BMI(45) Published studies show that there is a link between erectile dysfunction and obesity and metabolic syndrome and some studies have also identified it as an early marker of cardiovascular disease in overweight individuals. Thus, increased sexual difficulties experienced by the overweight male can contribute to their fertility problems(46).

\section{Study Objectives:}

To determine the association between BMI (body-mass index) and serum FSH levels in male patients.

To Assertain the association between BMI (body-mass index) and sperm parameters in male patients

To correlate the levels of serum FSH with infertility in male patients.

\section{Research Design:}

\section{Methadology:}

It was a case control study.

Settings:

The study was carried on the patients attending outpatient department (OPD) of Aziz Medical Hospital and Jinnah Post Graduate Medical Center (JPMC) from June 2010 to May 2011. Total no 147infertile study group were included in the study and 153 healthy fertile male were also included for better comparison and categorized as control fertile group (Control: Healthy normospermic males ) 
Association Of BMI with Follicular stimulating Hormone and with sperm parameters in males.

\subsection{Inclusion Criteria and Exclusion Criteria:}

- The study is based on samples collected from 147 infertile study group with semen analysis result during the period of Jan 2010 to march 2011. The inclusion criteria for control health male is age between $20-50$ years having children's and for cases was Idiopathic infertile male patients having age between $20-50$ years. Only patients having normal karyotyping were included in the study.

- The exclusion criteria included secondary infertility which includes infertility due to:

a. Obstructive Azoospermia, testicular insults (torsion, trauma), Cryptorchidism

b. Infections (mumps, orchitis, epididymitis)

c. Pelvic surgery or hernia repair

d. Patients with diabetic neuropathy

e. Patients taking anabolic steroids, non-steroidal anti inflammatory drugs (NSAIDS), cimetidine and spironolactone (which may affect spermatogenesis); sulfasalazine and nitrofurantion that affect sperm motility therapy for at least 74 days.

- Patients with psychiatric disorder were also excluded.

\section{Study Duration:}

The duration of study was one year.

\section{Sample Size:}

147 infertile male and 153 healthy fertile males .

\section{Sampling Techniques:}

Sampling technique was non probability, purposive sampling.

\section{Population of Interest (Human Subject /Material Etc.)}

This research involves human subjects, a detailed informed consent was taken before participation of individual $\&$ confidentiality of study subjects was maintained and this research did not include factors which can harm any human being.

\section{Methodology:}

Semen analysis was carried out on azoospermic and oligospermic men with an abstinence of 5 days according to WHO criteria. Patients were also subjected to hormonal assessment which comprises of serum FSH levels.

\section{Semen analysis:}

Semen analysis was used to assess the quantity and quality of spermatozoa and seminal fluid (47)After taking detailed history, the process of semen collection was verbally explained to the patients.

\section{Semen Sample Collection:}

a. The semen was obtained in a room separate from the main laboratory.

b. The sample was collected in a sterile wide mouthed plastic container which was marked with the name of the patient, registration code, the collecting time and date.

c. Sexual abstinence of minimum 1-3 days but not exceeding seven days was required before sample collection. The sample was examined within two hours after collection $(48,49)$

\section{Human Semen:}

Semen is a fluid ejaculated at the time of orgasm (50).

The analysis of the collected semen followed the protocol explained in WHO laboratory manual for the examination and processing of human semen (48).

There are two steps in semen analysis:

1. Macroscopic evaluation includes liquefaction time (above $60 \mathrm{~min}$. treat with bromelin), viscosity, appearance (smell, color), volume (quantity) and $\mathrm{pH}$.

2. Microscopic evaluation include aggregation of Spermatozoa, agglutination of Spermatozoa, sperm motility, concentration of sperms and total sperm number, morphology of spermatozoa, cells other than spermatozoa and sperm vitality.

3. Hormonal Analysis:

4. Hormone analysis was done by enzyme linked immunosorbent assay (ELISA)(51)

5. Storage and application:

6. The temperature of the reagent was brought to room temperature before the usage and kept in refrigerator

7. Collection of Blood Sample:

8. After obtaining consent of patient and normal subject, $10 \mathrm{ml}$ blood was drawn from each subject by venepuncture using plastic disposable syringe under aseptic measures in morning between $9 \mathrm{am}$ to $2 \mathrm{pm}$.

9. The blood was collected in a test tube or gel tube and allowed to clot and centrifuged for separation of serum within an hour of blood collection. After centrifugation serum was stored in deep freezer at $-20^{\circ} \mathrm{C}$ for subsequent hormonal analysis. Samples were analyzed in the batches of hundred to omit in between 
Association Of BMI with Follicular stimulating Hormone and with sperm parameters in males.

analytical variation. Serum PRL, T and FSH were measured by ELISA using kit supplied by DSI, Italy. (52)

\section{Determination of FSH:}

The quantitative determination of follicle stimulating hormone concentration in human serum by a microplate immunoenzymometric assay supplied by Monobind Inc. USA. (53)

\section{Ethical Consideration:}

The study was approved from Institutional Review Board (IRB), the Board of Advanced studies and Research (BASR) and funding committee of DUHS.

\section{Data Collection procedure:}

Detailed questionnaire was used as data gathering instrument. Patients from JPMC and Abbasi Shaheed Medical hospital, from the period of January 2010 to march 2011 were included in this research.

\section{Data Management and Statistical Analysis:}

The data was analyzed using Statistical Package for social sciences (SPSS) version 16.0, the analysis carried out was descriptive and independent $t$ test to find significance of mean value of lab parameter and discriminate functions to differentiate between azoospermia and oligospermia. Anova and person correlation coefficient was used to compare the association between BMI and reproductive hormone.

\section{Results:}

The study was carried out on 300 subjects which included 153 control healthy fertile male and 147 primary infertile male with mean age $33.30 \pm 7.18$ and $36.7 \pm 6.03$ and mean BMI $26.7 \pm 4.3$ and $24.3 \pm 3.7$ respectively (Table1). Study sample were collected from infertility clinics of Aziz medical Hospital Karachi and Jinnah post graduate medical hospital Karachi. Statistical analyses were performed using the Statistical Package for the Social Sciences version 16. Mean values were reported together with $+/$ - standard deviation (SD).All categorical variables were presented by frequencies and percentages. Mean differences between groups were tested statistically using the two sample independent $\mathrm{t}$ test. A p-value $<0.05$ was considered statistically significant.

\section{Age Distribution:}

Among study group $38.1 \%$ of infertile has $<30$ year of age, 44.2 were between $30-39$ and $15.6 \%$ were $40-49$ and $2 \%$ were $>50$ years of age. Whereas seem in healthy fertile group $67.3 \%$ were between $30-39,28.8 \%$ were $40-49$, and $4.6 \%$ were $>50$ years of age.

\section{Sperm Characteristics:}

The mean value of sperm count of infertile males $41.2 \pm 41.4 \mathrm{millions} / \mathrm{ml}$ with $95 \%$ C.I $(48.0,34.5)$ and fertile group mean sperm count was $112 \pm 23.9$ millions $/ \mathrm{ml}$ with $95 \%$ C.I $(116.0,108.4)$ and it is also shown that there is significant difference in sperm count between infertile male and healthy fertile group.

The common age group in infertile study group and controls were 20-40 years followed by mean age of infertile study group is $30.30 \pm$ at $95 \%$ C.I $(34.53,32.18)$ where as in control healthy males mean age is $36.7 \pm 6.3$ at 95\%C.I (37.68,35.7)years as shown in Table 15.

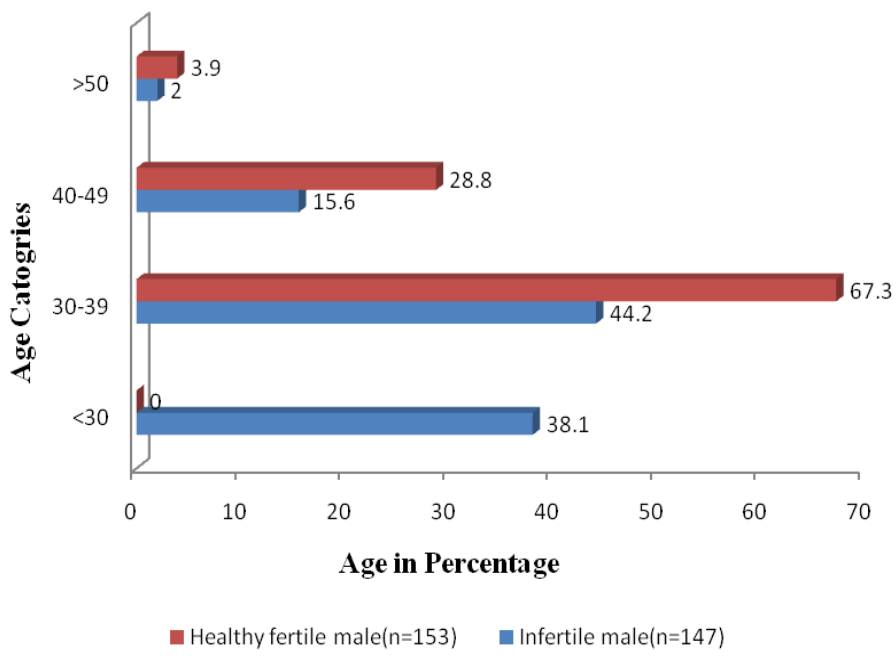


Association Of BMI with Follicular stimulating Hormone and with sperm parameters in males.

Figure.1 Shows distribution of study subjects (Infertile and fertile group) according to their age.

Table: 1 Descriptive statistics of fertile and infertile study subjects

\begin{tabular}{|c|c|c|c|c|c|c|c|}
\hline \multirow{3}{*}{ VARIABLES } & \multirow{3}{*}{$\begin{array}{l}\mathbf{p} \\
\text { value } \\
(< \\
\text { 0.0.5) }\end{array}$} & \multicolumn{3}{|c|}{ Infertile subjects } & \multicolumn{3}{|c|}{ Fertile study subjects } \\
\hline & & \multirow[t]{2}{*}{ Mean $_{ \pm}$S.D } & \multicolumn{2}{|c|}{$\begin{array}{l}\text { 95\% Confidence } \\
\text { Interval }\end{array}$} & \multirow[t]{2}{*}{ Mean $_{ \pm}$S.D } & \multicolumn{2}{|c|}{$\begin{array}{l}95 \% \\
\text { Confidence } \\
\text { Interval }\end{array}$} \\
\hline & & & Lower & Upper & & Lower & Upper \\
\hline Age(years) & 0.448 & $33.35 \pm 7.18$ & 32.18 & 34.53 & $36.7 \pm 6.03$ & 35.7 & 37.68 \\
\hline Weight(kg) & $<0.01$ & $75.4 \pm 12.6$ & 73.4 & 77.5 & $70.5 \pm 12.5$ & 68.05 & 72.0 \\
\hline Height $\left(\mathrm{m}^{2}\right)$ & 0.962 & $1.67 \pm 0.07$ & 1.66 & 1.68 & $1.7 \pm 0.7$ & 1.68 & 1.71 \\
\hline FBS & $<0.01$ & $99.7 \pm 34.3$ & 94.1 & 105.3 & $91.8 \pm 11.3$ & 89.6 & 94.1 \\
\hline BMI & $<0.01$ & $26.7 \pm 4.3$ & 26.0 & 27.5 & $24.3 \pm 3.7$ & 23.6 & 25.1 \\
\hline FSH(mIU/ml) & $<0.01$ & $20.7 \pm 1.0$ & 19.0 & 20.7 & $8.5 \pm 4.1$ & 7.8 & 9.1 \\
\hline Sperm Count & $<0.01$ & $41.2 \pm 41.46$ & 34.5 & 48.0 & $112 \pm 23.9$ & 108.4 & 116.0 \\
\hline
\end{tabular}

Table;2 Biophysical And Endocrine Profiles Of Studied (Infertile)Group With Their Mean (SD) And 95\% Confidence Interval

\begin{tabular}{|l|l|l|}
\hline Parameters & Mean( SD) & $\mathbf{9 5 \%}$ CI \\
\hline Age(years) & $33.30 \pm 7.2$ & $(32.1,34.48)$ \\
\hline BMI kg/m ${ }^{2}$ & $26.7 \pm 4.3$ & $(26.0,27.5)$ \\
\hline FSH (mIU/ml) & $20.7 \pm 1.0$ & $(19.0,20.7)$ \\
\hline
\end{tabular}

The mean age of the studied group was $26.7 \pm 4.3$ years with 32.1 years as the lower limit and 34.48 years as the upper limit of $95 \%$ confidence interval. Body mass index was also calculated after height and weight measurement, which was observed as $26.7 \pm 4.3 \mathrm{~kg} / \mathrm{m} 2$ with 26.0 as the lower limit and 27.5 as the upper limit of $95 \%$ of confidence interval. $20.7 \pm 1.0 \mathrm{mIU} / \mathrm{m}$ was discovered as the mean value for follicular stimulating hormone and had $19.0 \mathrm{mIU} / \mathrm{ml}$ as the lower limit and $20.7 \mathrm{mIU} / \mathrm{ml}$ as the upper limit of $95 \%$ confidence interval. Mean PRL hormone value was illustrated as $16.9 \pm 2.1 \mathrm{mIU} / \mathrm{ml}$ with 13.5 as the lower limit and 20.4 as the upper limit of $95 \%$ confidence interval.(Table: 2

We divided the studied group of Infertile male into three categories of serum FSH. $25.2 \%$ of infertile study group had normal range that is $1.0-14 \mathrm{mIU} / \mathrm{ml} .37 \%$ falls in the category ranging between $1-14 \mathrm{mIU} / \mathrm{ml} .72 .8 \%$ of patients had very high FSH that is above $28 \mathrm{mIU} / \mathrm{ml}$. Two persons have less than $1.0 \mathrm{mgIU} / \mathrm{ml}$.(Table :3)

Table: 3 Frequency Distribution Of FSH In Our Study Population

\begin{tabular}{|l|l|l|}
\hline Follicle stimulating hormone (FSH) $\mathbf{~ m g I U / m l ~}$ & $\mathbf{n = 1 4 7}$ & $\begin{array}{l}\text { Percentage } \\
\%\end{array}$ \\
\hline Less than 1.0 $\mathbf{~ m g I U / m l ~}$ & 3 & 2.0 \\
\hline $\mathbf{1 . 0 - 1 4 . 0 ~} \mathbf{~ m g I U / m l}$ & 37 & 25.2 \\
\hline Above $14.0 \mathrm{mgIU} / \mathrm{ml}$ & 107 & 72.8 \\
\hline
\end{tabular}

There is significant difference between reproductive hormones levels of infertile male and health control group. Mean value of FSH in case/infertile male was $20.7 \pm 1.0$ at $95 \%$ confidence interval. There as in control mean FSH is $8.5 \pm 4.1$. (Table.15)

Body Mass Index was also evaluated during the study. Amongst the total infertile subjects, the mean BMI was found to be $26.7 \mathrm{~kg} / \mathrm{m}^{2}$ with a standard deviation of $4.3 \mathrm{~kg} / \mathrm{m}^{2}$. In healthy fertile subjects, the mean BMI was found to be $24.3 \mathrm{~kg} / \mathrm{m}^{2}$ with a standard deviation of $3.7 \mathrm{~kg} / \mathrm{m}^{2}$. The minimum BMI observed in infertile subjects was $15.5 \mathrm{~kg} / \mathrm{m}^{2}$ and in fertile subjects $15.0 \mathrm{~kg} / \mathrm{m}^{2}$ while the maximum was found to be $37.88 \mathrm{~kg} / \mathrm{m}^{2}$ in infertile male subjects and $34.0 \mathrm{~kg} / \mathrm{m}^{2}$ in healthy fertile subjects. The mean BMI was found to differ significantly between the two groups $(\mathrm{p}<0.01)$.

According to the Asian Pacific criteria for BMI, only $29 \%$ infertile males and $35.3 \%$ fertile males fall in to the normal BMI category. Approximately $78.2 \%(n=115)$ infertile men were found to have BMI greater 
Association Of BMI with Follicular stimulating Hormone and with sperm parameters in males.

22.9 thus putting them to a greater health risk. Out of this $78.2 \%, 12.2 \%(\mathrm{n}=18)$ patients were classified as overweight, $40.1 \%(\mathrm{n}=59)$ as obese type I and $25.9 \%(\mathrm{n}=38)$ as obese type II. On the other hand, only $62.2 \%$ men from the fertile group were found to have BMI greater than 22.9. 22.9\% $(n=35)$ were over-weight, $26.8 \%(n=41)$ were classified as obese type I, and $10.5 \%(n=16)$ were obese type II. $2 \%(n=3)$ cases and $4.6 \%(n=7)$ controls were observed to have BMI lesser than 18.5. The two groups were found to have statistically significant difference among each other $(<0.01)$ (Table :4).

Table: 4 Showing frequency and percentage of study groups lying in the different groups of BMI according to the new BMI criteria for Asia Pacific

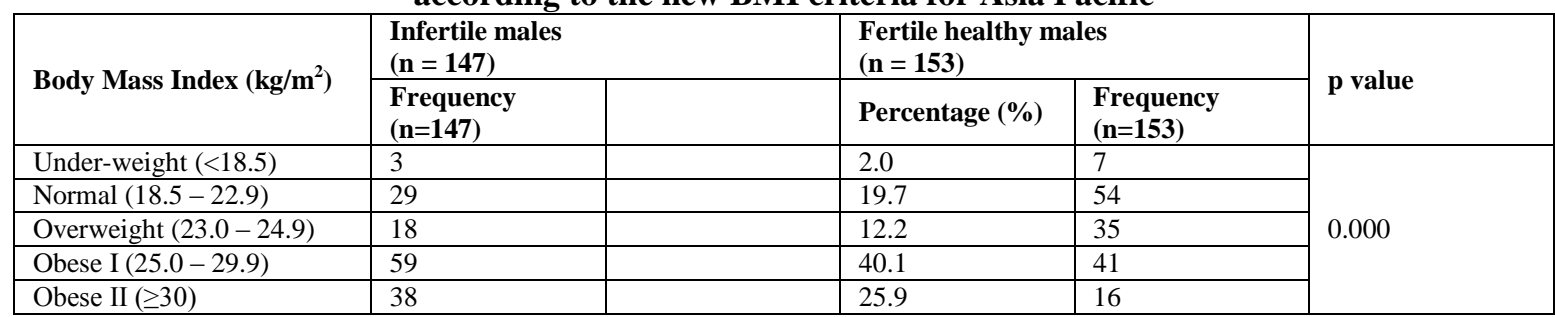

A comparison between the various parameters determining the quality of sperms was done between the infertile and fertile men during the study shown by Table:5

The mean volume of sperm observed in the fertile group of males $(n=153)$ was found to be $3.43 \mathrm{ml}$ with a standard deviation of $1.08 \mathrm{ml}$. The infertile group of males $(\mathrm{n}=147)$ showed a mean volume of $1.22 \mathrm{ml}$ with a standard deviation of $0.421 \mathrm{ml}$. There was a significant difference observed in the mean volume of sperm in the fertile and the infertile group of individuals $(\mathrm{p}<0.01)$.

On an average, about $56.46\left(\times 10^{6} / \mathrm{ml}\right)$ live sperms were found during the semen analysis of fertile group with a standard deviation of $26.32\left(\mathrm{x} 10^{6} / \mathrm{ml}\right)$. The mean live sperm count in infertile group was found to be 2.47 ( $\mathrm{x}$ $\left.10^{6} / \mathrm{ml}\right)$ with a standard deviation of $5.03\left(\mathrm{x} 10^{6} / \mathrm{ml}\right)$. A significant difference was seen in the total number of live sperm count seen in the fertile and the infertile group $(\mathrm{p}<0.01)$.

Another parameter to determine the sperm vitality of individuals was the $\mathrm{pH}$ of the semen. The mean $\mathrm{pH}$ found in the group of fertile men was 7.65 with a standard deviation of 0.28 . The mean $\mathrm{pH}$ observed amongst the infertile males was found to be 7.76 with a standard deviation of 0.59 . There was a significant difference seen in the $\mathrm{pH}$ of the semen of the fertile and the infertile males $(\mathrm{p}<0.01)$.

The morphology of the sperm is also an important parameter that contributes towards male infertility. It was observed that in the fertile group of individuals, a mean of $53.46 \%$ were morphologically normal sperms with a standard deviation of $21.16 \%$ while in the infertile group, a mean of $12.33 \%$ morphologically normal sperms were found during the semen analysis with a standard deviation of $17.63 \%$. There was a significant difference observed in the percentage of morphologically normal sperms found in the fertile and the infertile group of men $(\mathrm{p}<0.01)$.

It was observed that the mean percentage value of the motile sperms present in fertile men was $56.11 \%$ with a standard deviation of $7.46 \%$ while in infertile group; the mean value was $14.42 \%$ with a standard deviation of $23.38 \%$. Out of these, $36.00 \%$ sperms with a standard deviation of $8.45 \%$ were found to have rapid linear progression among the fertile men while in infertile group only $9.82 \%$ sperms with a standard deviation of $15.88 \%$ were found to have a rapid linear progression. $20.03 \%$ sperms with a standard deviation of $9.91 \%$ were found to have slow/non-linear progression among the fertile men while in infertile group $6.51 \%$ sperms with a standard deviation of $10.27 \%$ were found to have a slow/non-linear progression. $44.11 \%$ sperms with a standard deviation of $7.24 \%$ were non-progressive among the fertile men while in infertile group $16.74 \%$ sperms with a standard deviation of $25.04 \%$ were non-progressive. There was a significant difference observed in the percentage of motile sperms, rapid progression, slow/non-linear progression and non-progression found in the fertile and the infertile group of men $(\mathrm{p}<0.01)$.

Table: 5 Showing comparison between sperm parameters among infertile men and fertile

\begin{tabular}{|l|l|l|l|}
\hline Parameter & $\begin{array}{l}\text { Fertile group (n=147) } \\
\text { Mean } \pm \text { SD }\end{array}$ & $\begin{array}{l}\text { Infertile Group (n=153) } \\
\text { Mean } \pm \text { SD }\end{array}$ & p value \\
\hline Volume (ml) & $3.43 \pm 1.08$ & $1.22 \pm 0.41$ & $<0.01$ \\
\hline pH & $7.65 \pm 0.28$ & $7.76 \pm 0.59$ & 0.044 \\
\hline Live Sperm Count 10 $/ \mathbf{m l}$ & $56.46 \pm 26.32$ & $2.47 \pm 5.03$ & $<0.01$ \\
\hline Morphology & & & $<0.01$ \\
\hline Normal form (\%) & $53.46 \pm 21.16$ & $12.33 \pm 17.63$ & $<0.01$ \\
\hline Motility & & & $<0.01$ \\
\hline motile sperm & $56.11 \pm 7.46$ & $14.42 \pm 23.38$ & $<0.01$ \\
\hline Rapid linear progression (\%) & $36.00 \pm 8.45$ & $9.82 \pm 15.88$ & \\
\hline
\end{tabular}


Association Of BMI with Follicular stimulating Hormone and with sperm parameters in males.

\begin{tabular}{|l|l|l|l|}
\hline Slow/non-linear progression (\%) & $20.03 \pm 9.91$ & $6.51 \pm 10.27$ & $<0.01$ \\
\hline Non-progressive (\%) & $44.11 \pm 7.24$ & $16.74 \pm 25.04$ & $<0.01$ \\
\hline
\end{tabular}

\section{Coefficient Correlation:}

As attempt has made to investigate the linear association between the continuous variables by applying the standardized co-relation co-efficient statically method. In this study the different seminal and sperm characteristic as well as hormones total 7 variable were co-efficiently co-related. The results obtained from the application of such an approach are presented in Table6.

There is a strong significant correlation between BMI and serum FSH level. Strong positive correlation between FSH and BMI $(r=0.596, p<0.05)$.

Sperm concentration found to be significantly lower in men with a BMI greater than 25 as compared to men with BMI less than 25.

A significant negative relationship for sperm count, although a lower sperm concentration was only statically significant in obese men compared with normal weight men $(\mathrm{P}<0.05)$. No association was found for semen volume and sperm morphology. A significant negative correlation was found for sperm motility $(r=-0.231, p=$ $0.05)$.

Table: 6 Correlation Between BMI With Different Variable Studied

\begin{tabular}{|l|l|l|l|l|}
\hline & BMI & $\begin{array}{l}\text { Sperm } \\
\text { motility }\end{array}$ & $\begin{array}{l}\text { sperm } \\
\text { count }\end{array}$ & FSH \\
\hline BMI & 1 & $0.138^{*}$ & $-0.250^{*}$ & $0.596^{*}$ \\
\hline Sperm motility & & 1 & $-0.231^{*}$ & $0.277^{*}$ \\
\hline sperm count & & & 1 & $-0.486^{*}$ \\
\hline FSH & & & & 1 \\
\hline
\end{tabular}

\section{*. Correlation is significant at the 0.05 level}

\section{Discussion}

Male infertility has become a very common problem and causes severe mental anguish and anxiety to sufferers. It is difficult to assess prevalence of infertility in developing countries. The perceptual experience of infertility in Pakistan is almost same as in different parts of the world, except the fact that infertile males are reluctant to report for evaluation in our country. Demographic health surveys data provided by WHO (2004) shows that female primary infertility prevalence in Nepal is 6\%, in Korea 2\%, in Indonesia $7 \%$,India 3\%, Bangladesh 4\% and Pakistan is 4\% However the prevalence of male infertility the in Pakistan is 7\%.Rahim et al in Pakistan has concluded in their study (151) that $50 \%$ cases of infertility are due to male factor. The frequency of infertility was $12 \%$, due to male factors is $45 \%, 41.64 \%$ by female, unexplained in $7.50 \%$ and both were involved in $5.70 \%$ of infertile study group. Among various causes of male infertility, obesity is one of the leading factor(91) but the relationship of BMI with spermatogenesis and reproductive hormone is certainly not straightforward.

\section{BMI As Marker of Body Fat:}

Various studies has included BMI ,as marker of body fat (54) although waist hip ratio is a better predictor of reproductive outcome (55) as BMI does not distinguish between android body fat distribution and gynaecoid fatty distribution. BMI is not a perfect measure of body fat and can be reliable as surrogate predictor of body fat, its validity and thresholds for excessive body fat or obesity have been questioned (56) but it has been recently used to measure or estimate body fat and obesity(57). Deurenberg in Netherlands concluded BMI as a sensitive body fat predictor by using a age and gender specific formula (58).In France, Wittemer et al, used BMI to measure an outcome of IVF procedure in female and concluded mean that ratio of folliclestimulating hormone-luteinizing hormone increased significantly in accordance to BMI levels (58).

Another study conducted by Jorge et al in Boston, Massachusetts determined the relationship of BMI with DNA integrity and semen quality (59).In 2007 by systematic review Maheshwari et al concluded that obesity is a major reproductive health problem and raised BMI were associated with decline in conception rate (54).

\section{Association between Serum FSH and BMI:}

In our study mean values of FSH was $8.5 \mathrm{mIU} / \mathrm{m}$ for healthy control group $20.75 \mathrm{mIU} / \mathrm{ml}$ for infertile mal.Higher levels of FSH in obese males are in accordance with various studies conducted worldwide. Wu FCW et al (60) found twenty one azoospermic male with raised FSH serum level and concluded that increase in oestradiol $(46 \pm 6 \pm 12 \pm 6 \mathrm{pg} / \mathrm{ml})$ is due to excess stimulation of sertoli cells by GnRH stimulation. A case study 
conducted by Mara Y Roth et al in 2008 presented a case of 29-year-old infertile male with morbid obesity, gynecomastia, hypogonadism and low testicular volume. His BMI was $54.5 \mathrm{~kg} / \mathrm{m} 2$ and his sperm concentration was almost at undetectable levels. Case study typically explains the dispute in diagnosing, managing and treatment of male infertility with obesity is the primary causative factor. Treatment with an aromatase inhibitor, anastrozole, led to normalization of the patient's testosterone, luteinizing hormone and folliclestimulating hormone levels, suppression of serum estradiol levels, and normalization of spermatogenesis and fertility(61).

Recently in 2011 Sarwat noticed in her study (62) that excessive body fat are expected to cause alteration in male reproductive hormonal profile.In her study male subjects with BMI $>20$ have higher serum levels of Leptin and showed a statistical significant positive correlation with LH (p < 0.01) and FSH ( $<$ $0.002)$ and a significant negative correlation with $\mathrm{T}(\mathrm{p}<0.001)$, There study also pointed out that BMI appears to have significant association with serum leptin levels.

Negative correlation of BMI with $\mathrm{T}(\mathrm{r}=-0.38)$, FSH $(\mathrm{r}=-0.22)$, and inhibin B levels $(\mathrm{r}=-0.21)$ has been reported by Pauli (206), no correlation of BMI or skin fold thickness with semen parameters (sperm density, volume, motility, or morphology)was found. Inhibin B level correlated significantly with sperm motility $(\mathrm{r}=0.23)$. Men with paternity had lower BMIs $(28.0 \mathrm{~kg} / \mathrm{m} 2 \mathrm{vs.} 31.6 \mathrm{~kg} / \mathrm{m} 2)$ and lower skin fold thickness $(24.7$ $\mathrm{mm}$ vs. $34.1 \mathrm{~mm}$ ) as compare to infertile men.Similar results were found in Danish population by Tina Kold Jensen. Serum T, sex hormone-binding globulin (SHBG), and inhibin B all showed decreased trend with increasing trend of BMI. Serum FSH was higher among slim men with a BMI $<20 \mathrm{~kg} / \mathrm{m} 2 \mathrm{had}$ a reduction in sperm concentration and total sperm count of $28.1 \%$ (95\% confidence interval [CI] 8.3\%-47.9\%) and $36.4 \%$ (95\% CI $14.6 \%-58.3 \%)$, respectively, and men with a BMI $>25 \mathrm{~kg} / \mathrm{m} 2$ had a reduction in sperm concentration and total sperm count of $21.6 \%$ (95\% CI $4.0 \%-39.4 \%$ ) and $23.9 \%$ (95\% CI $4.7 \%-43.2 \%$ ), respectively, compared to men with BMI between $20-25 \mathrm{~kg} / \mathrm{m} 2$. Semen volume and percentage of motile spermatozoa were not affected by BMI(63).

\section{Association between BMI and spermatogenesis:}

Semen is composed of secretions of seminal vesicles, prostate glands, cowper's glands and sperms. During emission, contraction of the vas deferens coincides with contraction of the muscular coats of the two accessory sex glands and results into mixing of the sperms with all the components of semen (64) .

The secretion from the seminal vesicles comprises approximately $60 \%$ of the seminal volume. These glands are the primary source of fructose. The seminal vesicles also secrete semenogelins, which induce coagulation of semen after ejaculation. The alkaline secretion of the prostate, which makes up about $30 \%$ of the volume, is high in citrate, zinc, spermine and acid phosphatase. PSA is a serine protease that liquefies coagulated semen after a few minutes. The predominant buffers in semen are phosphate and bicarbonate. A third accessory gland, the bulbourethral gland ,empty into the penile urethra in response to sexual excitement prior to emission and ejaculation. This secretion is high in mucus, which lubricates, cleanses and buffers the urethra (64)

Various studies proved a strong positive association between BMI and defective spermatogenesis In obese males with BMI $\geq 35 \mathrm{~kg} / \mathrm{m}^{2}$ sperm with high DNA damage were significantly more numerous in obese men than in normal-weight men. No association was found between Body mass index and sperm concentration, motility, or morphology. The ejaculate volume of semen showed decreased trend with increasing BMI levels(64).

Also concluded by various studies that raised BMI play crucial role on regulation of HPT axis suggest that impaired sperm production as a result of unopposed feed back by hypothalamus on testicular Leydig cells. Data also shows no link between BMI and steroid hormone but our study is in agreement with report of decrease T level.

We did not found statically significant link between sperm concentration sperm, morphology or sperm mortality among various BMI categories. Although semen volume was lower in male having BMI > 30 relative to control group with normal BMI (29/25). In addition the sperm concentration was dramatically lower in study group having BMI > 35. In addition, the study provides sufficient rationale for a complete analytical profile of the infertile male in order to accurately diagnose the cause of infertility and to propose proper therapy. Finally, the study demonstrates that the Pakistani infertile male (who are highly disturbed emotionally) are reluctant to undergo fertility assessment.

\section{Limitations:}

1. Because of the ethical issue males resist to accept their stigma of infertility

2. Family studies could not be performed.

3. DNA studies for mutation were not performed

\subsection{Weakness/strength:}

1. Only male from the age $20-45$ age were included in the study

2. We cannot rule out internal anatomical deformity. 


\section{Conclusion :}

Hence we concluded that the BMI $>30$ is associated with altered reproductive hormone levels in obese males.

\section{Recommendation :}

We recommend that BMI can be used as an indicator for obesity and use to measure the risk not only for obesity but for reproductive health measure.

\section{References:}

[1]. Pasqualotto FF. Investigation and assisted reproduction in the treatment of male infertility. Brazilian Journal of Gynecology and Obstetrics. 2007;29:103-12.

[2]. Rowe PJ, Comhaire FH, Hargreave TB, Mahmoud AMA. WHO manual for the standardized investigation, diagnosis and management of the infertile male: Cambridge Univ Pr 2000.

[3]. Maduro MR, Lo KC, Chuang WW, Lamb DJ. Genes and male infertility: what can go wrong? Journal of Andrology. 2003;24:485.

[4]. Simoni M, Bakker E, Krausz C. EAA/EMQN best practice guidelines for molecular diagnosis of y-chromosomal microdeletions. State of the art 2004. International Journal of Andrology. 2004:240-9.

[5]. Ferlin A, Raicu F, Gatta V, Zuccarello D, Palka G, Foresta C. Male infertility: role of genetic background. Reproductive Biomedicine Online. 2007;14:734-45.

[6]. Habbema J, Collins J, Leridon H, Lvers J, Lunenfeld B, teVelde E. Towards less confusing terminology in reproductive medicine. a proposal Human Reproduction. 2004;19(7):1497-1501

[7]. Greenhall E, Vessey M. The prevalence of subfertility: a review of the current confusion and a report of two new studies. Obstetrical \& Gynecological Survey. 1991;46(6):397.

[8]. Rowe PJ, Comhaire FH. WHO manual for the standardized investigation, diagnosis and management of the infertile male. Cambridge University Press; 2000.

[9]. Chillón M, Casals T, Mercier B, Bassas L, Lissens W, Silber S,ClaudineV Mutations in the cystic fibrosis gene in patients with congenital absence of the vas deferens. New England Journal of Medicine. 1995;332(22):1475-80.

[10]. Srinivasan S, Bunch DO, Feng Y, Rodriguiz RM, Li M, Ravenell RL, et al. Deficits in reproduction and pro-gonadotropin-releasing hormone processing in male Cpefat mice. Endocrinology. 2004 ;145(4):2023-34.

[11]. Greil AL. Infertility and psychological distress: a critical review of the literature. Social Science \& Medicine. 1997;45(11):1679704.

[12]. Pakistan. National A. Pakistan Population Assessment 2003. Government of Pakistan; 2003.

[13]. Crabo BG, Hunter AG. Sperm maturation and epididymal function. J, J Sciarra, C Markland and JJ Speidel (Ed) Control of Male Fertility Harper and Row, Hagerstown, Md. 1975.

[14]. Dacheux JL, Chevrier C, Lanson Y. Motility and Surface Transformations of Human Spermatozoa during Epidiymal Transita. Annals of the New York Academy of Sciences. 1987;513(1):560-3.

[15]. Muoio DM, Newgard CB. Obesity-related derangements in metabolic regulation. Annu Rev Biochem. 2006;75:367-401.

[16]. Behre HM, Yeung CH, Nieschlag E. Diagnosis of male infertility and hypogonadism. Andrology: male reproductive health and dysfunction. 1997(chap 6):87-111.

[17]. Sallmen M, Sandler DP, Hoppin JA, Blair A, Baird DD. Reduced fertility among overweight and obese men. Epidemiology. 2006 ;17(5):520-3.

[18]. Esposito K, Giugliano F, Ciotola M, De Sio M, D'Armiento M, Giugliano D. Obesity and sexual dysfunction, male and female. International journal of impotence research. 2008;20(4):358-65.

[19]. Bostofte E, Serup J, Rebbe H. Interrelations among the characteristics of human semen, and a new system for classification of male infertility. Fertility and sterility. 1984;41(1):95.

[20]. Kort HI, Massey JB, Elsner CW, Mitchell-Leef D, Shapiro DB, Witt MA, et al. Impact of body mass index values on sperm quantity and quality. Journal of andrology. 2006;27(3):450-59

[21]. Hinz S, Rais-Bahrami S, Kempkensteffen C, Weiske WH, Miller K, Magheli A. Effect of obesity on sex hormone levels, antisperm antibodies, and fertility after vasectomy reversal. Urology. 2010;76(4):851-6.

[22]. Tsai EC, Matsumoto AM, Fujimoto WY, Boyko EJ. Association of bioavailable, free, and total T with insulin resistance. Diabetes Care. 2004;27(4):861-68.

[23]. Wass P, Waldenström U, Rössner S, Hellberg D. An android body fat distribution in females impairs the pregnancy rate of in-vitro fertilization-embryo transfer. Human Reproduction. 1997;12(9):2057-2060

[24]. Bellver J, Ayllon Y, Ferrando M, Melo M, Goyri E, Pellicer A. Female obesity impairs in vitro fertilization outcome without affecting embryo quality. Fertility and Sterility ;93(2):447-54.

[25]. Baker HWC. Relative incidence of etiological disorders in male infertility. Male reproductive dysfunction. 2005:341-72.

[26]. Griffin D, Finch K. The genetic and cytogenetic basis of male infertility. Human Fertility. 2005;8(1):19-26.

[27]. World health organization (WHO) and demographic health surveys (DHS), . WHO Press 2004. (2004).271.

[28]. Abbas Aflatoonian MD, Seyedhassani SM, Tabibnejad N. The epidemiological and etiological aspects of infertility in Yazd province of Iran. Iranian Journal of Reproductive Medicine. 2009;7(3):117-22.

[29]. Baker HWC. Relative incidence of etiological disorders in male infertility. Male reproductive dysfunction. 2005:341-72.

[30]. Tüttelmann F, Gromoll J, Kliesch S. Genetics of male infertility]. Der Urologe Ausg A. 2008;47(12):1561-62.

[31]. O'Flynn OB, Katherine L, Varghese AC, Agarwal A. The genetic causes of male factor infertility: a review. Fertility and Sterility. 2010;93(1):1-12.

[32]. Simoni M, Weinbauer GF, Gromoll J, Nieschlag E, editors. Role of FSH in male gonadal function; Journal of Family Planning and Reproductive Health Care. 1999;31(3):192

[33]. Skakkebaek NE, Giwercman A, De Kretser D. Pathogenesis and management of male infertility. Lancet. 1994;343(8911):1473-8.

[34]. Rogoza A, Mierzejewski W, Puzio M. Detection and treatment of hyperprolactinemia in male infertility]. Ginekologia polska. 1994;65(2):75-9.

[35]. Merino G, Carranza-Lira S, Martinez-Chéque JC, Barahona E, Moran C, Bermudez JA. Hyperprolactinemia in men with asthenozoospermia, oligozoospermia, or azoospermia. Systems Biology in Reproductive Medicine. 1997;38(3):201-6. 
[36]. Nielsen TL, Hagen C, Wraae K, Brixen K, Petersen PH, Haug E, et al. Visceral and subcutaneous adipose tissue assessed by magnetic resonance imaging in relation to circulating androgens, sex hormone-binding globulin, and luteinizing hormone in young men. Journal of Clinical Endocrinology \& Metabolism. 2007;92(7):2696-2705

[37]. Rodger F. Yen and Jaffe's Reproductive Endocrinology: Physiology, Pathophysiology, and Clinical Management. Journal of Family Planning and Reproductive Health Care. 2005;31(3):189-192.

[38]. Batra SK. Sperm transport through vas deferens: review of hypotheses and suggestions for a quantitative model. Fertility and Sterility. 1974;25(2):186.

[39]. Fejes I, Koloszar S, Zavaczki Z, Daru J, Szollosi J, Pal A. Effect of body weight on T/estradiol ratio in oligozoospermic patients. Arch Androl. 2006 ;52(2):97-102.

[40]. Laaksonen DE, Niskanen L, Punnonen K, Nyyss Ã Inen K, Tuomainen TP, Valkonen VP. The metabolic syndrome and smoking in relation to hypogonadism in middle-aged men: a prospective cohort study. Journal of Clinical Endocrinology \& Metabolism. 2005;90(2):712-19.

[41]. Lima N, Cavaliere H, Knobel M, Halpern A, Medeiros-Neto G. Decreased androgen levels in massively obese men may be associated with impaired function of the gonadostat. International journal of obesity. 2000;24(11):1433-7.

[42]. Cassidy SB, Driscoll DJ. Prader-Willi syndrome. European Journal of Human Genetics. 2008;17(1):3-13.

[43]. Ogden CL, Carroll MD, Curtin LR, McDowell MA, Tabak CJ, Flegal KM. Prevalence of overweight and obesity in the United States, 1999-2004. JAMA: the journal of the American Medical Association. 2006;295(13):1549-55.

[44]. Wang P, Mariman E, Renes J, Keijer J. The secretory function of adipocytes in the physiology of white adipose tissue. Journal of Cellular Physiology. 2008;216(1):3-13.

[45]. Riedner CE, Rhoden EL, Ribeiro EP, Fuchs SC. Central obesity is an independent predictor of erectile dysfunction in older men. The Journal of Urology. 2006;176(4):1519-23.

[46]. Hofny ERM, Ali ME, Abdel-Hafez HZ, Kamal EED, Mohamed EE, Abd EA, et al. Semen parameters and hormonal profile in obese fertile and infertile males. Fertility and Sterility. 2010;94(2):581-4.

[47]. WHO laboratory manual for the Examination and processing of human semen. WHO Press;. 2010.; 5th ed.: p. 271.

[48]. Castilla JA, Alvarez C, Aguilar J, González-Varea C, Gonzalvo MC, Martinez L. Influence of analytical and biological variation on the clinical interpretation of seminal parameters. Human Reproduction. 2006;21(4):847-51.

[49]. Gardner DG, Shoback DM, Greenspan FS. Greenspan's basic \& clinical endocrinology. McGraw-Hill Medical; 2007.

[50]. Comhaire F, Vermeulen L. Human semen analysis. Human reproduction update. 1995;1(4):343-51.

[51]. H J Hansen ea. Solving the Problem of Antibody Interference in Commercial "Sandwich"-Type Immunoassays of Carcino embryonic Antigen, . GlinChem. 1989.; 35:146-51.

[52]. Signorella AP, Hymer WC. An enzyme-linked immunosorbent assay for rat PRL* 1. Analytical Biochemistry. 1984;136(2):372-81.

[53]. Hennies M, Voglmayr JK, Dietrich E, Stollmann M, Moeller R, Holtz W. Hormonal Response of Female Goats to Active Immunization against a Recombinant Human Inhibin subunit, and establishment of an Enzyme linked Immunosorbent Assay for Caprine Follicle stimulating Hormone. Reproduction in Domestic Animals. 2001;36(2):65-71.

[54]. Rehana Rahim, Majid. SS. Aetiological factors of Infertility. J Postgrad Med Inst. Jul 2011;7(21 ):393-7. .

[55]. Maheshwari A, Stofberg L, Bhattacharya S. Effect of overweight and obesity on assisted reproductive technology-a systematic review. Human Reproduction Update. 2007;13(5):433-45.

[56]. Akpinar E, Bashan I, Bozdemir N, Saatci E. Which is the best anthropometric technique to identify obesity: body mass index, waist circumference or waist-hip ratio? Collegium Antropologicum. 2007;31(2):387-97.

[57]. Deurenberg P, Weststrate JA, Seidell JC. Body mass index as a measure of body fatness: age-and sex-specific prediction formulas. British Journal Nutrion. 1991;65(2):105-14.

[58]. Christiane Wittemer, Ohl J, Marc Bailly, Bettahar-Lebugle K, Nisand I. Does Body Mass Index of Infertile Women Have an Impact on IVF Procedure and Outcome? Journal of Assisted Reproduction and Genetics 1999;17( 10, ): 547-52.

[59]. Chavarro JE, Toth TL, Wright DL, Meeker JD, Hauser R. Body mass index in relation to semen quality, sperm DNA integrity, and serum reproductive hormone levels among men attending an infertility clinic2005. Fertility and Sterility.93(7):2222-31.

[60]. Wu FCW, Swanston IA, Baird DT. Raised plasma oestrogens in infertile men with elevated levels of FSH. Clinical Endocrinology. 1982;16(1):39-47.

[61]. Roth MY, Amory JK, Page ST. Treatment of male infertility secondary to morbid obesity. Nature Clinical Practice Endocrinology \& Metabolism. 2008;4(7):415-9.

[62]. Sarwat Jahan RB, Shakeel Ahmed, Salma Kafeel. Leptin levels in infertile males. J Coll Physicians Surg Pak 2011;21((7)):393-7.

[63]. Jensen TK, Andersson AM, Jørgensen N, Andersen AG, Carlsen E, Petersen J, et al. Body mass index in relation to semen quality and reproductive hormonesamong 1,558 Danish men. Fertility and Sterility. 2004;82(4):863-70.

[64]. Chemes HE, Rawe VY. Sperm pathology: a step beyond descriptive morphology. Origin, characterization and fertility potential of abnormal sperm phenotypes in infertile men. Human Reproduction Update. 2003;9(5):405-12

[65]. Johanisson E, Campana A, Luthi R, De Agostini A. Evaluation ofround cells' in semen analysis: a comparative study. Human reproduction update. 2000;6(4):404-10.

[66]. Kalyani RR, Gavini S, Dobs AS. Male hypogonadism in systemic disease. Endocrinology \&Metabolism Clinics of North America. 2007;36(2):333-48. 